\title{
ESTIMATIVAS DE PARÂMETROS FENOTÍPICOS E AMBIENTES DAS PRODUÇÕES DE LEITE NO DIA DO CONTROLE E EM 305 DIAS DE LACTAÇÃO EM VACAS DA RAÇA GIR ${ }^{1}$
}

\author{
IVAN LUZ LEDIC ${ }^{2}$ \\ RUI DA SILVA VERNEQUE ${ }^{3}$ \\ MÁRIO LUIZ MARTINEZ ${ }^{3}$
}

\begin{abstract}
RESUMO - Dados de 32.779 controles mensais, de 3.605 lactações em 305 dias (PL305), de 2.082 vacas Gir, filhas de 281 touros, com partos ocorridos de 1987 a 1999, em 11 rebanhos, foram usados com o objetivo de verificar os fatores que afetam a produção de leite no dia do controle (PLDC) em avaliações na raça Gir. Foram realizadas análises univariadas das PLDC1 a PLDC10 e da PL305 pelo método de máxima verossimilhança restrita, sob modelo animal, incluindo as três primeiras lactações como medidas repetidas de um mesmo animal, diferenciado conforme o rebanho, o ano e a estação do parto (PL305) ou do controle (PLDC1 a PLDC10), a idade da vaca ao parto, a ordem do parto e do intervalo parto-primeiro controle (ipc) na PLDC1. As médias observadas e os respectivos desvios-padrão
\end{abstract}

\begin{abstract}
(kg) para PLDC1 a PLDC10 e PL305 foram: $11,97 \pm 4,64 ; \quad 11,93 \pm 4,68 ; \quad 10,98 \pm 4,40 ; \quad 10,18 \pm 4,12$; $9,66 \pm 3,88 ; \quad 9,20 \pm 3,69 ; \quad 8,63 \pm 3,51 ; \quad 8,08 \pm 3,33$; $7,59 \pm 3,27 ; 7,22 \pm 3,15$ e $2.746,17 \pm 1.299,90$. A produção máxima ocorreu no $23^{\circ}$ dia, conforme o ipc. Ocorreu grande variação em relação ao ano e estação, conforme a característica considerada, sem haver tendência definida. As diferenças entre as produções dos rebanhos foram acima de $50 \%$. Nos primeiros quatro controles, as produções foram muito afetadas pela idade da vaca e as vacas com idade entre 70 a 100 meses apresentaram produções mais elevadas; na PL305, a produção aumentou até 88 meses de idade. As produções de leite das terceiras ordens foram mais altas em relação aos do segundo e primeiro partos, com diferenças acima de $11 \%$.
\end{abstract}

TERMOS PARA INDEXAÇÃO: Bovino de leite, controle leiteiro, melhoramento animal.

\section{ESTIMATES OF PHENOTYPIC AND ENVIRONMENTAL PARAMETERS OF MILK PRODUCTION AT THE CONTROL DAY AND 305 DAYS OF LACTATION IN GIR BREED COWS}

\begin{abstract}
Data of 32,779 monthly milk production, of 3,605 lactations in 305 days (PL305), of 2,082 Gir breed cows, daughters of 281 sires, calving from 1987 to 1999, in 11 herds, were utilized to verify the factors that affect the milk production in the control day (PLDC) in evaluations of the Gir breed. Univariates analysis on PLDC1 to PLDC10 and P1305 were performed utilizing the restricted maximum likelihood method within an animal model, which included the three first lactations as replicate measures of the same dams unit. Animals were grouped according to the criterion of herd, year, season, calving-age, calving-order and to the interval calving-first control (ipc) in PLDC1. The observed averages $(\mathrm{kg})$ and the respective standard deviations for PLDC1 at PLDC10 and
\end{abstract}

PL305 were: $11.97 \pm 4.64 ; \quad 11.93 \pm 4.68 ; 10.98 \pm 4.40$ $10.18 \pm 4.12 ; 9.66 \pm 3.88 ; 9.20 \pm 3.69 ; 8.63 \pm 3,51 ; 8.08 \pm 3.33$; $7.59 \pm 3.27 ; 7.22 \pm 3.15$ and $2,746.17 \pm 1,299.90$. The maximum production happened on $23^{\circ}$ day, according to the ipc. There was greater variation in relation to the year and season, according to the considered trait, without defined trend. The differences among the herds productions were above $50 \%$. In the first four controls the productions were extremely affected by calving-age and the cows with age between 70 to 100 months presented higher productions; in the PL305 the production increased up to 88 months of age. The milk productions of the third calving-order were higher them the second and first calving, with difference above $11 \%$.

1. Parte da tese defendida na FCAV/UNESP de Jaboticabal

2. Veterinário, Pesquisador, DSc. Embrapa Gado de Leite - Caixa Postal 351, 38001-970, Uberaba, MG; ivanledic@epamiguberaba.com.br

3. Pesquisadores, DSc. Embrapa Gado de Leite - Rua Eugênio do Nascimento 610, 36038-330, Juiz de Fora, MG. 


\section{INTRODUÇÃO}

A medida padrão convencionada de produção de leite é o rendimento em 305 dias de lactação (PL305) e a seleção de reprodutores, das raças leiteiras, tem sido baseada nesse critério produtivo. Os estudos sobre a viabilidade de utilização da produção de leite no dia do controle (PLDC), para estimar parâmetros genéticos, fenotípicos e ambientes das características produtivas, visando a auxiliar a seleção em gado de leite, são bem antigos (MADDEN et al., 1959; SEARLE, 1961; LAMB e MCGILLIARD, 1967).

Com esse procedimento, é possível reduzir os custos em razão do menor número de controles por lactação e/ou do número de visitas do controlador, podendo ocorrer, ainda, encurtamento do intervalo de gerações. Vacas com apenas uma medida de produção podem ser incluídas nas análises, melhorarando a acurácia das estimativas dos valores genéticos preditos dos touros, minimizando vícios por descarte de lactações incompletas que ocorreriam nas avaliações com a PL305 (FERREIRA, 1999).

Já Freeman (1998) informou que o modelo utilizado para análise das PLDC não está claro e que efeitos genéticos e de ambiente podem estar confundidos. Assim, estudos com animais criados em nossas condições devem ser efetuados quanto à hipótese de utilizar da PLDC como critério de seleção em gado de leite.

\section{MATERIAL E MÉTODOS}

Dados de 32.779 controles mensais, de 3.605 lactações em 305 dias, de 2.082 vacas da raça Gir, filhas de 281 touros, com partos ocorridos de 1987 a 1999, em 11 rebanhos, foram usados com o objetivo de verificar os fatores que afetam a produção de leite no dia do controle (PLDC1 a PLDC10) e em 305 dias de lactação (PL305). Foram realizadas análises univariadas, por meio do sistema MTDFREML (BOLDMAN et al., 1995), sob modelo animal, incluindo as três primeiras lactações como medidas repetidas da vaca, diferenciadas conforme o rebanho, estação e ano do parto (na PL305) ou do controle (nas PLDC), ordem do parto, idade da vaca e do intervalo parto-primeiro controle na PLDC1.

\section{RESULTADOS E DISCUSSÃO}

As médias observadas, os desvios-padrão e os coeficientes de variação $(\mathrm{CV})$ para produção de leite no dia do controle leiteiro e para produção de leite em 305 dias de lactação podem ser visualizadas na Tabela 1 .

TABELA 1 - Número de observações, médias observadas, desvios-padrão e coeficientes de variação (CV) para produção de leite no dia do controle (PLDC1 a PLDC10) e para produção de leite em 305 dias de lactação (PL305).

\begin{tabular}{ccccc}
\hline Características & Observações & Médias (kg) & Desvios-padrão & CV (\%) \\
\hline PLDC1 & 2.719 & 11,97 & 4,64 & 38,77 \\
PLDC2 & 3.291 & 11,93 & 4,68 & 39,23 \\
PLDC3 & 3.256 & 10,98 & 4,40 & 40,07 \\
PLDC4 & 3.268 & 10,18 & 4,12 & 40,47 \\
PLDC5 & 3.160 & 9,66 & 3,88 & 40,16 \\
PLDC6 & 3.115 & 9,20 & 3,69 & 40,11 \\
PLDC7 & 3.019 & 8,63 & 3,51 & 40,67 \\
PLDC8 & 2.883 & 8,08 & 3,33 & 41,21 \\
PLDC9 & 2.631 & 7,59 & 3,27 & 43,08 \\
PLDC10 & 2.252 & 7,22 & 3,15 & 43,63 \\
PL305 & 3.185 & $2.746,17$ & $1.299,90$ & 47,33 \\
\hline
\end{tabular}

Ciênc. agrotec., Lavras. V.27, n.4, p.921-926, jul./ago., 2003 
Os CVs foram elevados e aumentaram com o avançar da lactação, com valor mais elevado na PL305. Foram maiores que os citados nos trabalhos de Gadini (1985), Machado (1997) e Ferreira (1999), os quais apresentaram valores de $20 \%$ a $30 \%$. Os altos CVs encontrados refletem, principalmente, desuniformidade de produções entre os rebanhos estudados. A diferença entre as produções dos rebanhos chegou a $66 \%$ (de 5,80 a $16,84 \mathrm{~kg}$ ), 64\% (de 6,21 a 17,06 kg), 61\% (de 6,14 a $15,77 \mathrm{~kg}$ ), $59 \%$ (de 6,05 a $14,78 \mathrm{~kg}$ ), $58 \%$ (de 5,85 a $13,96 \mathrm{~kg}$ ), $56 \%$ (de 5,76 a $13,19 \mathrm{~kg}$ ), $55 \%$ (de 5,62 a $12,41 \mathrm{~kg}$ ), 53\% (de 5,39 a 11,52 kg), 51\% (de 5,23 a $10,56 \mathrm{~kg}$ ) e $52 \%$ (de 4,75 a $9,84 \mathrm{~kg}$ ) nas PLDC1 a PLDC10, respectivamente, e 63\% (de 1.615,62 a $4.373,80 \mathrm{~kg}$ ) na PL305. Teixeira (1998) verificou que o efeito de rebanho foi responsável por 20 a 30\% das diferenças de produções de leite.

Em relação ao ano e à estação do parto ou do controle, houve grande variação conforme a característica considerada, sem haver tendência definida dos efeitos. Teixeira (1998) constatou que efeitos de ano e estação são responsáveis por 10 a $20 \%$ da variação entre as produções e estão associados às condições climáticas, mudança de manejo, fatores econômicos e genéticos.

Pode-se averiguar, também, que houve alteração conforme a fase da lactação, estando o pico de produção no primeiro controle. Observando o efeito do intervalo parto-primeiro controle sobre a PLDC1 (Figura 1), constata-se que a produção máxima ocorreu no $23^{\circ}$ dia pós-parto. Danell (1982) e Machado (1997) consideraram a influência do intervalo parto-primeiro controle, tendo em vista esse ser muito variável no primeiro controle.

A diminuição, a partir do segundo controle, foi mais abrupta no terceiro e quarto controles (redução de 0,95 e $0,80 \mathrm{~kg}$ de leite em cada controle, respectivamente), mantendo declínio quase que constante a partir daí (queda de aproximadamente $0,50 \mathrm{~kg}$ de leite por controle). Cabe salientar que a PLDC10 $(7,22 \mathrm{~kg})$ foi elevada para considerar encerramento da lactação, principalmente em se tratando de animais zebuínos, representando queda de apenas 39,68\% em relação à PLDC1, estando muito acima da produção média do rebanho nacional.

A curva de lactação, observada neste estudo, não segue a mesma tendência apresentada por Schutz et al. (1990), Stanton et al. (1992), Machado (1997) e Ferreira (1999) para a raça Holandês, em que o pico de produção ocorreu entre o segundo e terceiro controles. Os resultados deste trabalho estão de acordo com os de Rao e Sundaresan (1979), com rebanho Sahiwal e Bianchini Sobrinho (1984) e Gadini (1985) em rebanhos Gir, os quais encontraram pico da produção no primeiro mês pós-parto. Essa pode ser uma singularidade da raça Gir, um Bos taurus indicus, que atinge o máximo de produção leiteira já no primeiro mês da lactação.

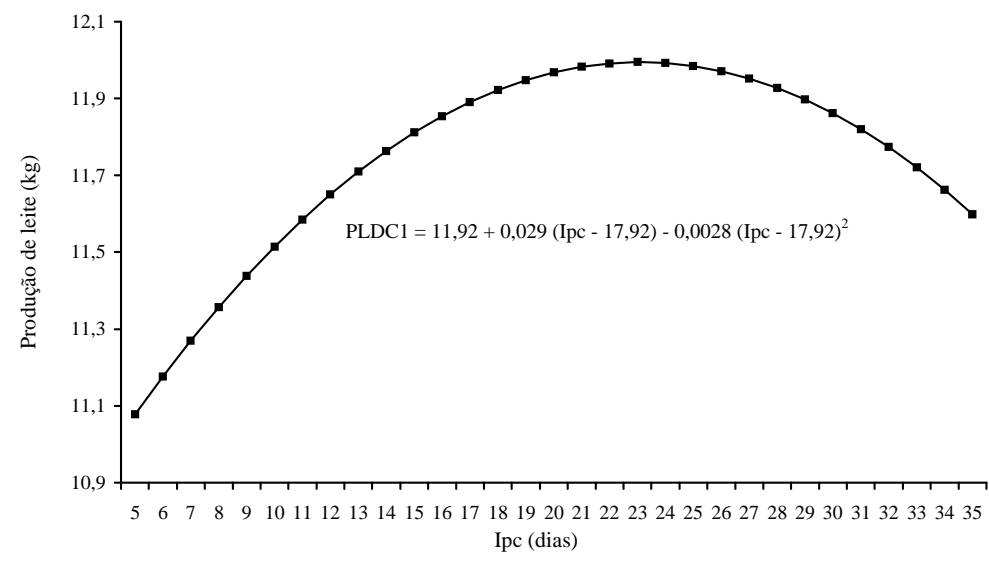

FIGURA 1 - Médias esperadas para a produção de leite no primeiro controle (PLDC1) em função do intervalo parto-primeiro controle (Ipc). 
O efeito da idade da vaca ( $i$, em meses) sobre as PLDC pode ser visualizado na Figura 2, conforme as equações: PLDC1 $=11,92+0,13(\mathrm{i}-57,63)-0,002(\mathrm{i}$ $-57,63)^{2} ;$ PLDC2 $=11,93+0,12(\mathrm{i}-57,50)-0,002(\mathrm{i}$ $-57,50)^{2} ;$ PLDC3 $=10,98+0,10(\mathrm{i}-57,38)-0,002(\mathrm{i}$ $-57,38)^{2} ;$ PLDC4 $=10,18+0,09(\mathrm{i}-57,60)-0,002(\mathrm{i}$ $-57,60)^{2} ;$ PLDC5 = 9,66 +0,08 $(\mathrm{i}-57,62)-0,001(\mathrm{i}-$ $57,62)^{2} ;$ PLDC6 $=9,20+0,07(\mathrm{i}-57,64)-0,001(\mathrm{i}-$ $57,64)^{2} ;$ PLDC7 $=8,63+0,06(i-57,43)-0,0008(i-$ $57,43)^{2} ;$ PLDC8 $=8,08+0,05(\mathrm{i}-57,55)-0,0006(\mathrm{i}-$ $57,55)^{2} ;$ PLDC9 $=7,59+0,04(\mathrm{i}-57,52)-0,0004(\mathrm{i}-$
$57,52)^{2} ;$ PLDC10 = 7,22 + 0,03 $(\mathrm{i}-57,86)-0,0004(\mathrm{i}-$ $57,86)^{2}$.

Afere-se que no início da lactação, nos primeiros quatro controles, a produção de leite dos animais foi mais afetada pela idade do animal que no restante dessa, e as vacas com idade entre 70 a 100 meses apresentaram produções mais elevadas no começo da lactação.

$\mathrm{O}$ efeito da idade da vaca ao parto (i, em meses) sobre a PL305 pode ser verificado na Figura 3. A PL305 aumentou com a idade da vaca até 88 meses, decrescendo a seguir.

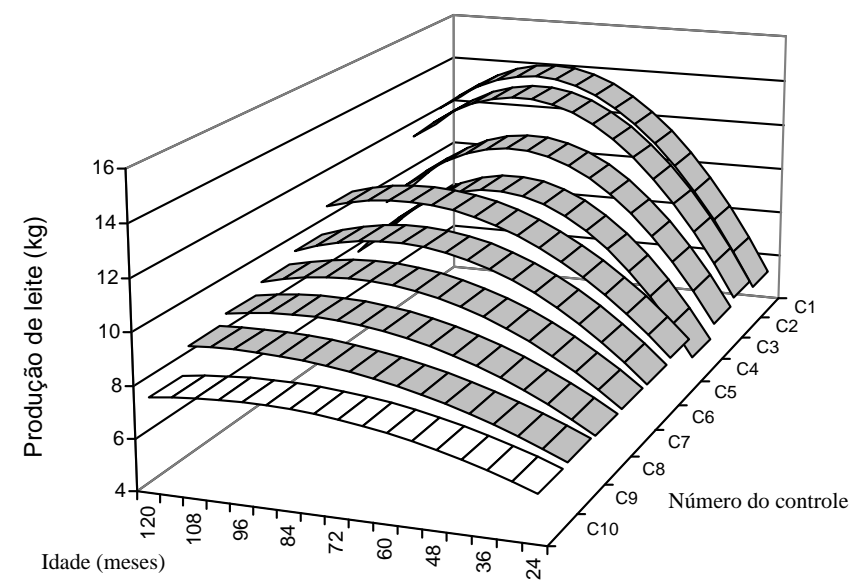

FIGURA 2 - Médias esperadas para os controles mensais de produção de leite (PLDC1 a PLDC10), conforme a idade da vaca ao parto (i).

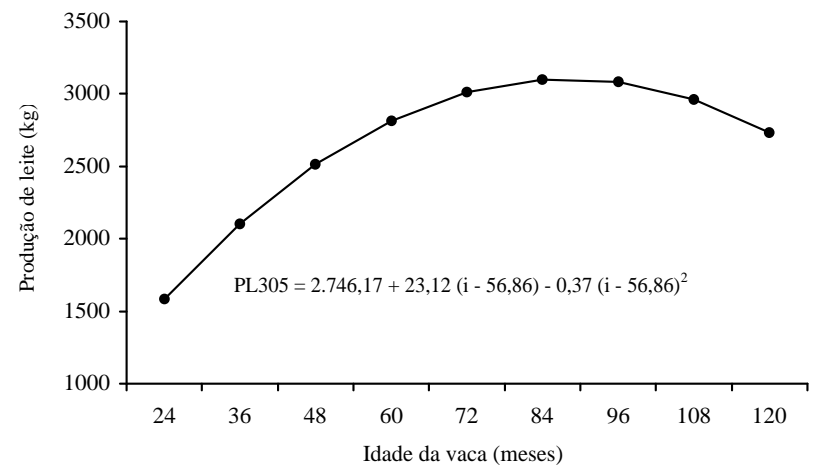

FIGURA 3 - Médias esperadas da produção de leite em 305 dias de lactação (PL305), conforme a idade da vaca ao parto (i).

Ciênc. agrotec., Lavras. V.27, n.4, p.921-926, jul./ago., 2003 
Da mesma forma, as produções de leite das terceiras ordens de parto foram mais elevadas em relação aos do segundo e primeiro (menor produção) partos, com diferenças de $29 \%$ (de 10,00 a $14,18 \mathrm{~kg}$ ); $27 \%$ (de 10,16 a $13,93 \mathrm{~kg}$ ); $25 \%$ (de 9,51 a $12,68 \mathrm{~kg}$ ); $22 \%$ (de 8,95 a $11,55 \mathrm{~kg}$ ); $20 \%$ (de 8,62 a $10,78 \mathrm{~kg}$ ); $19 \%$ (de 8,26 a $10,18 \mathrm{~kg}$ ); $16 \%$ (de 7,92 a $9,46 \mathrm{~kg}$ ); $16 \%$ (de 7,48 a $8,87 \mathrm{~kg}$ ); $15 \%$ (de 7,05 a $8,34 \mathrm{~kg}$ ); $11 \%$ (de 6,86 a $7,72 \mathrm{~kg}$ ) e $22 \%$ (de 2.416,52 a $3.120,22 \mathrm{~kg}$ ), para PLDC1 a PLDC10 e PL305, respectivamente.

Corroborando esses resultados, Danell (1982) e Machado (1997) observaram decréscimo da influência do efeito da idade da vaca com o avanço da lactação. Machado (1997) também verificou um aumento da produção com a idade até um certo limite, na maturidade fisiológica do animal, diminuindo a seguir.

\section{CONCLUSÕES}

Os fatores considerados no modelo neste estudo são peculiares a todas as vacas; contudo, influenciaram de forma diferente as diversas PLDC e PL305.

Tendo em vista que a acurácia das avaliações genéticas dependem, além da utilização de metodologia apropriada, do modelo adequado, então, são necessários novos estudos com as PLDC para identificar fatores específicos a cada controle, os quais seriam assumidos como circunstanciais nos modelos de PL305 e que diminuiriam a precisão das avaliações.

Modelos mais refinados devem ser pesquisados para poderem agregar e conjugar múltiplas PLDC a PL305, visando a minimizar viés por descarte de lactações incompletas que não seriam consideradas nas avaliações somente com PL305.

\section{REFERÊNCIAS BIBLIOGRÁFICAS}

BIANCHINI SOBRINHO, E. Estudo da curva de lactação de vacas da raça Gir. 1984. 88 f. Tese (Doutorado em Genética) - Faculdade de Medicina de Ribeirão Preto, Universidade de São Paulo, Ribeirão Preto, 1984.

BOLDMAN, K. G.; KRIESE, L. A.; VAN VLECK, L. D.; KACHMAN, S. D. A manual for use of MTDFREML. A set of programs to obtain estimative of variances and covariances [DRAFT]. Beltsville: Department of Agriculture, Agricultural Research, 1995. $125 \mathrm{p}$.
DANELL, B. Studies on lactation yield and individual test day yields of Swedish dairy cows. II. Estimates of genetic and phenotypic parameters. Acta Agricultural Scandinavia, Stockholm, v. 32, n. 1, p. 83-91, 1982.

FERREIRA, W. J. Parâmetros genéticos para produção de leite no dia do controle de vacas da raça Holandesa. 1999. 103 f. Dissertação (Mestrado em Zootecnia) - Universidade Federal de Viçosa, Viçosa, 1999.

FREEMAN, M. E. Dairy cattle breeding. In: WORLD CONGRESS ON GENETICS APPLIED TO LIVESTOCK PRODUCTION, 6., 1998, Armidale. Proceedings... Armidale: U.N.E., 1998. v. 23, p. 293294.

GADINI, C. H. Influências genéticas e ambientes sobre a curva de lactação de um rebanho Gir. 1985. 96 f. Dissertação (Mestrado em Genética) - Faculdade de Medicina de Ribeirão Preto, Universidade de São Paulo, Ribeirão Preto, 1985.

LAMB, R. C.; McGILLIARD, L. D. Usefulness of part records to estimate the breeding values of dairy cattle. Journal of Dairy Science, Champaign, v. 50, n. 9, p. 1459-1467, 1967.

MACHADO, S. G. Parâmetros genéticos e de ambiente da produção de leite no dia do controle da primeira lactação de vacas da raça Holandesa. 1997. 76 f. Dissertação (Mestrado em Zootecnia) - Faculdade de Ciências Agrárias e Veterinárias, Universidade Estadual Paulista, Jaboticabal, 1997.

MADDEN, D. E.; McGILLIARD, L. D.; RALSTON, N. P. Relations between test-day milk production of Holstein cows. Journal of Dairy Science, Champaign, v. 42 , n. 2 , p. $319-326,1959$.

RAO, M. K.; SUNDARESAN, D. Influence of environment and heredity on the shape of lactation curves in Sahiwal cows. Journal of Agricultural Sciences, Cambridge, v. 92, p. 393-401, 1979.

SEARLE, S. R. Part lactations II. Genetic phenotypic studies of monthy milk fat yield. Journal of Dairy Science, Champaign, v. 44, n. 2, p. 282-294, 1961.

SCHUTZ, M. M.; HANSEN, L. B.; STEUERNAGEL, G. R. Variation of milk, fat, protein and somatic cells for dairy cattle. Journal of Dairy Science, Champaign, v. 73, n. 2, p. 484-493, 1990. 
STANTON, T. L.; JONES, L. R.; EVERETT, R. W.; KACHANAN, S. D. Estimating milk, fat and protein lactation curves with a test day model. Journal of Dairy Science, Champaign, v. 75, n. 6, p. 1691-1700, 1992.
TEIXEIRA, N. M. Introdução ao melhoramento genético do gado de leite. In: MELHORAMENTO GENÉTICO DE BOVINOS LEITEIROS PARA TÉCNICOS DA COOPERATIVA DE PRATA-MG, 1998, Prata. Curso... Prata: EMBRAPA/CNPGL, 1998. p. 40-60. 